\title{
Excitatory Amino Acid-mediated Responses and Synaptic Potentials in Medial Pontine Reticular Formation Neurons of the Rat in vitro
}

\author{
David R. Stevens, Robert W. McCarley, and Robert W. Greene \\ Harvard Medical School and Veterans Affairs Medical Center, Brockton, Massachusetts 02401
}

Neurons of the medial pontine reticular formation (mPRF) are involved in the execution of numerous behaviors including initiation of locomotion, eye movements, startle responses, and rapid eye movement sleep phenomena. Approximately half of the afferent projections to MPRF neurons come from within the reticular formation (Shammah-Lagnado et al., 1987). In spite of the importance of reticulo-reticular connections, virtually nothing is known about transmitters mediating these synapses. In order to identify a candidate excitatory neurotransmitter, the actions of excitatory amino acids (EAAs) on the membrane properties of mPRF neurons recorded in rat brainstem slices in vitro were studied. Standard intracellular recording methods, including single-electrode voltage clamp, were used to examine the postsynaptic actions of EAAs. We also tested whether EAA antagonists block EPSPs evoked by stimulation of the contralateral reticular formation in the slices. MPRF neurons responded to both non-NMDA and NMDA agonists. NMDA-induced conductances were voltage dependent and depressed by physiological concentrations of magnesium. Stimulation of the contralateral reticular formation elicited EPSPs that were depressed by the general EAA antagonist kynurenate. Evoked EPSPs were partially depressed by 6,7-dinitroquinoxaline2,3-dione. The evoked EPSP was further reduced by the NMDA antagonist ( \pm )-2-amino-5-phosphonopentanoic acid in some cases. These results suggest that excitatory reticulo-reticular neurotransmission is mediated by an EAA. Both non-NMDA and NMDA receptors contribute to EAA neurotransmission in the mPRF formation and play an integral role in reticular formation function.

The medial pontine reticular formation (mPRF), and specifically the nucleus reticularis pontis oralis and nucleus reticularis pontis caudalis contain neurons that are involved in numerous behaviors. These two nuclei contain reticulospinal neurons (Grantyn et al., 1980; Mitani et al., 1988) that are involved in motor activities (see review by Peterson, 1979), such as locomotion (Jordan, 1991) and oculomotor saccades (see review by Steriade and McCarley, 1990). A strong argument has also been made for participation of mPRF neurons in the startle response (Davis, 1984). The activity of mPRF neurons is altered during

Received Mar. 23, 1992; revised May 25, 1992; accepted May 28, 1992.

This work was supported by the Department of Veterans Affairs, NIMH Grant R 37 39,683, and Army Defense Grant 87PP7811. We thank Jacqueline Weider for excellent technical assistance and help with manuscript preparation and Dr. Jennifer Luebke for her helpful critique of an earlier version of the manuscript.

Correspondence should be addressed to Robert Greene, Neuroscience Lab $151 \mathrm{C}$, V.A.M.C., 940 Belmont Street, Brockton, MA 02401.

Copyright $(\mathcal{C}) 1992$ Society for Neuroscience $0270-6474 / 92 / 124188-07 \$ 05.00 / 0$ changes in behavioral state, and there is evidence that neurons of the $\mathrm{mPRF}$ are involved in the expression of the phenomenology of rapid eye movement (REM) sleep (see discussion by Steriade and McCarley, 1990).

It has been reported that approximately half of the afferent projections of these nuclei are from other reticular formation neurons (Shammah-Lagnado et al., 1987). In spite of the apparent importance of reticulo-reticular projections, little is known of the transmitters involved in these nctworks. McCarlcy and coworkers have reported the presence of excitatory synaptic connections between neurons of the mPRF (McCarley et al., 1987; Ito and McCarley, 1987). These authors have indicated that in the majority of neurons examined in vivo, fast EPSPs with monosynaptic latency were evoked. Fast EPSPs of the type indicated by those studies are typically mediated by either nicotinic cholinergic synapses or excitatory amino acid (EAA) synapses. There are few cholinergic (ChAT-positive) neurons in the mPRF (Jones, 1990); thus, the neurotransmitter mediating fast excitatory synaptic transmission of reticulo-reticular synapses is probably an EAA. This conclusion is supported by an increasing number of reports of behavioral responses elicited by local application of EAA agonists into the pontomedullary reticular formation (Lai and Siegel, 1988, 1991; Noga et al., 1988).

Based on binding studies, EAA receptors exhibit relatively low density in the reticular formation (Monaghan and Cotman, 1982; Rainbow et al., 1984, 1987; Cotman and Monaghan, 1987). The low binding density of EAA receptors may simply reflect the presence of dense myelinated fibers and resulting lower density of neuronal somata in the reticular formation and have no bearing on the importance of these receptors in reticular formation synaptic transmission.

We have used intracellular recording methods to examine the responses to EAAs and their role in synaptic transmission in $m P R F$ neurons in an in vitro brainstem slice preparation. We find that each of the three ionotropic EAA receptors is present on mPRF neurons and that both non-NMDA and NMDA receptors may be activated by synaptically released neurotransmitter in the mPRF.

\section{Materials and Methods}

Long-Evans hooded rats of either sex aged 8-20 d were anesthetized and then decapitated. The brain was rapidly removed and immersed in ice-cold artificial cerebrospinal fluid (ACSF). The brainstem was removed with a cut caudal to the pons and a cut at the level of the superior colliculus. Much of the cerebellum was removed with a horizontal cut that spared the pons. This tissue block was then affixed to a chuck with cyanoacrylate glue, immersed in cold oxygenated ACSF, and sliced on a vibratome to obtain three or four $500-\mu \mathrm{m}$-thick coronal slices containing the $\mathrm{mPRF}$

The slices were incubated in a holding chamber at room temperature 

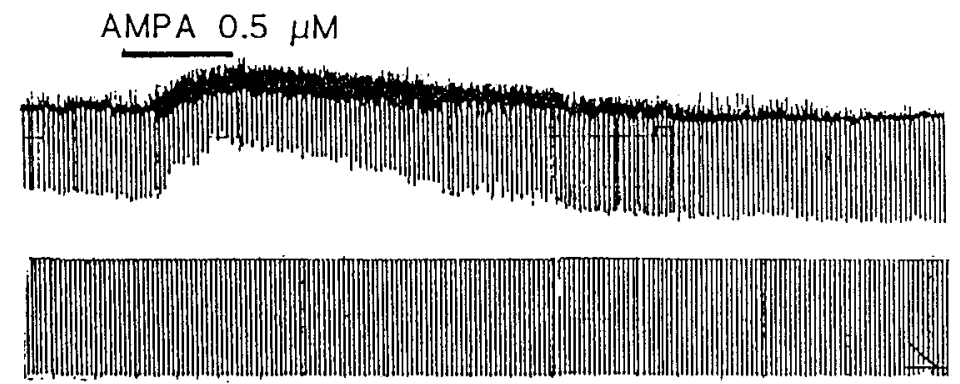

B

Control

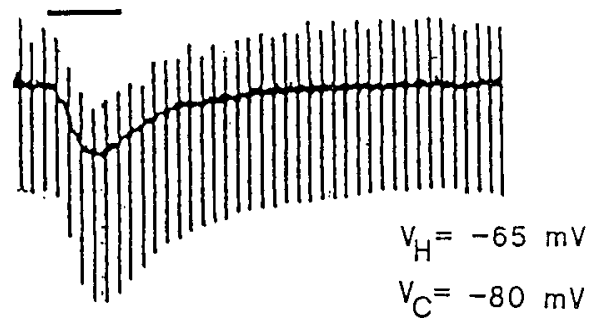

Kynurenate $1 \mathrm{mM}$

AMPA $0.5 \mu \mathrm{M}$

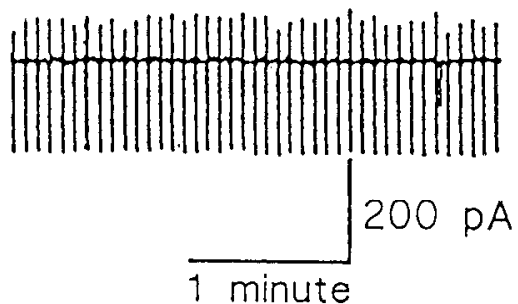

\section{$20 \mathrm{mV}$ \\ $250 \mathrm{pA}$ \\ 1 minute}

Figure 1. AMPA depolarizes MPRF neurons. $A$, Chart record demonstrates the depolarization with increased firing resulting from application of AMPA $(0.5$ $\mu \mathrm{M}$; the thickened baseline is due to increased firing; action potentials are truncated by the chart recorder). There is a decrease in the amplitude of potentials resulting from square current pulses ( $300 \mathrm{pA}$; downward deflections) consistent with a decrease in input resistance. $B$, Under voltage clamp, AMPA application results in an inward (downward) current. Current required to achieve command steps ( -65 to -80 $\mathrm{mV}$; downward deflections) was increased demonstrating an increase in membranc conductance. The inward current and conductance increase elicited by AMPA were blocked by kynurenate $(1 \mathrm{mM})$.

in oxygenated ACSF prior to transfer to a recording chamber where they were submerged and superfused with ACSF of the following composition (in M): $\mathrm{NaCl}, 124 ; \mathrm{KCl}, 3.75 ; \mathrm{KH}_{2} \mathrm{PO}_{4}, 1.25 ; \mathrm{MgCl}_{2}, 1.3 ; \mathrm{CaCl}_{2}$, 2.5; $\mathrm{NaHCO}_{3}, 26.0$; glucose, 10 ; bubbled with $95 \% \mathrm{O}_{2}, 5 \% \mathrm{CO}_{2}$ to maintain oxygenation and $\mathrm{pH}$; and kept at $30 \pm 2^{\circ} \mathrm{C}$. The following drugs were applied as part of the perfusate or by pressure ejection at 10-fold higher concentration: kainate, glutamic acid, strychnine, kynurenic acid (Sigma), 6,7-dinitroquinoxaline-2,3-dione (DNQX), $(R, S)$ $\alpha$-amino-3-hydroxy-5-methylisoxazole-4-propionic acid hydrobromide (AMPA), ( \pm )-2-amino-5-phosphonopentanoic acid (AP5) (Research Biochemicals Inc.).

Intracellular recordings were obtained using microelectrodes pulled from standard-thickness fiber-filled capillary borosilicate glass filled with $2 \mathrm{M} \mathrm{KCl}$ or $2 \mathrm{M} \mathrm{K}$-methylsulfate and having resistances in the range of $60-120 \mathrm{M} \Omega$. Voltage and current recordings were made either in the bridge mode or in the single-electrode voltage-clamp mode of an Axoclamp 2A (Axon Instruments Inc., Burlingame, CA) amplifier. During voltage recordings, bridge balance was monitored on an oscilloscope, and, while in single-electrode voltage clamp, head-stage voltage transients were monitored to assure adequate settling time. Recordings were digitized and stored on videotape and on disk. Input resistance was monitored by passage of square current pulses while in the bridgebalance mode.

\section{Results}

The actions of EAA agonists were examined on 78 neurons of the mPRF. $\Lambda$ pplication of glutamate $(10-100 \mu \mathrm{M})$ in the superfusion medium resulted in depolarization and increased firing in all neurons tested $(n=7)$.

\section{Non-NMDA responses}

Application of AMPA $(0.3-1 \mu \mathrm{M})$, the reference agonist for ionotropic quisqualate receptors (Honore et al., 1982), resulted in depolarization of the membrane potential (Fig. 1A). This response was accompanied by a decrease in the potential excursion induced by hyperpolarizing square current steps, indi-

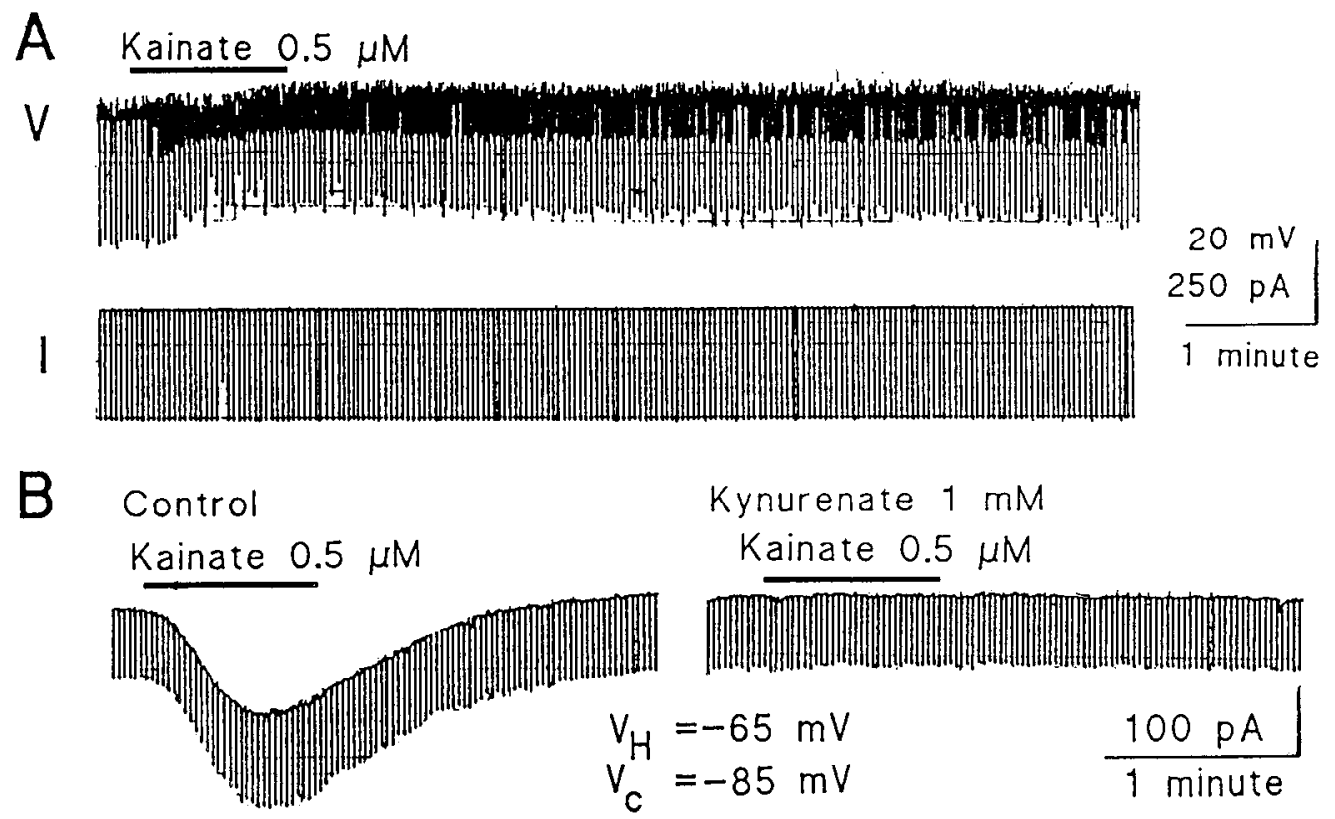

Figure 2. Kainate depolarizes mPRF neurons. $A$, Kainate $(0.5 \mu \mathrm{M})$ treatment results in a depolarization and increased firing activity. Potentials associated with $300 \mathrm{pA}$ current pulses were decreased in the presence of kainate consistent with a decrease in input resistance. $B$, Under voltage clamp, kainate $(0.5 \mu \mathrm{M})$ caused an inward current associated with an increase in conductance $(0.5 \mu \mathrm{M}$ TTX present $)$. The action of kainate was blocked by kynurenate (l $\mathrm{mM}$ ). 

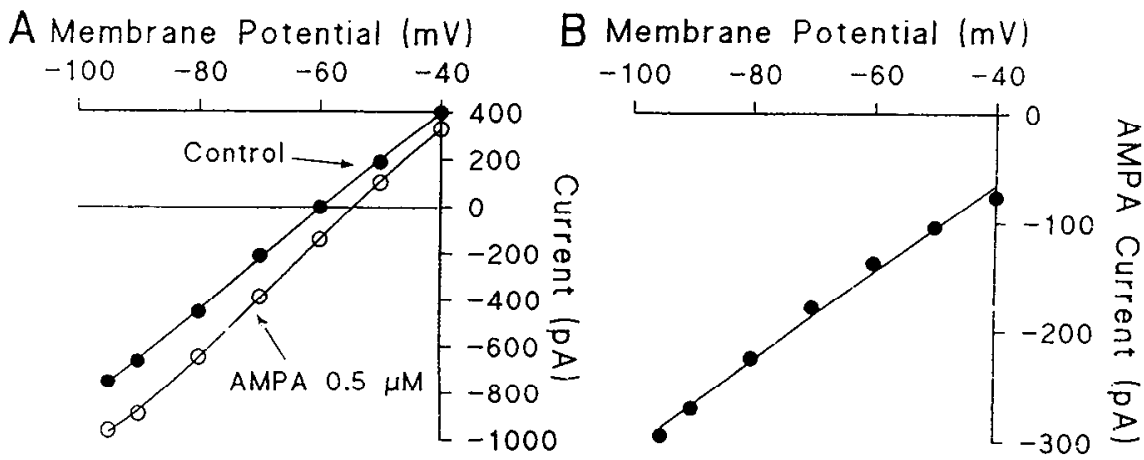

Figure 3. AMPA and kainate activate

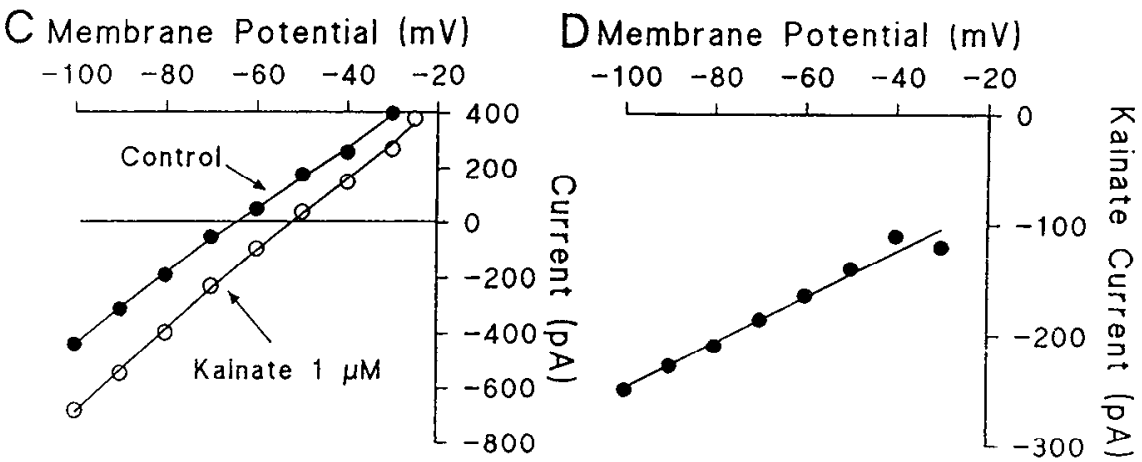
currents with linear voltage dependence. $A$, The steady-state $I / V$ relations of an mPRF neuron in control perfusate is compared to that in the presence of AMPA $(0.5 \mu \mathrm{M}), B$, Subtraction of the AMPA $I / V$ curve from the control $I / V$ curve results in the current activated by AMPA, which is linear over the range examined. $C$, Kainate $(1 \mu \mathrm{M})$ shifted the $I / V$ relation inward over the entire range. $D$, The subtracted kainate-induced current was linear over the range examined.

cating that there was a decrease in input resistance. Under voltage-clamp control, AMPA treatment resulted in an inward current (Fig. $1 B$ ). During AMPA treatment, the current required to achieve voltage step commands was increased, directly demonstrating an increased membrane conductance. The action of AMPA was blocked by treatment with the nonselective EAA antagonist kynurenic acid (Fig. $1 B ; n=3 ; 1 \mathrm{mM}$ ).

Application of kainic acid also resulted in a depolarization (Fig. 2A). This response was also associated with a decrease in input resistance. Under voltage clamp, kainate treatment resulted in an inward current with increased membrane conductance (Fig. $2 B ; n=10$ ). The kainate response was blocked by $1 \mathrm{mM}$ kynurenate (Fig. $2 B ; n=5$ ).
Non-NMDA responses typically result from increased conductance of a mixed cation-selective channel (Mayer and Westbrook, 1985). These conductances are typically linear with respect to membrane potential with reversal potentials near $0 \mathrm{mV}$ (Mayer and Westbrook, 1987). We examined the voltage dependence of AMPA and kainate responses. The steady-state current-voltage $(I / V)$ relation was determined using ramp voltage commands (from -100 to $-30 \mathrm{mV}$ at $2.5 \mathrm{mV} / \mathrm{sec}$ ). $I / \mathrm{V}$ relations are shown in Figure 3. The whole-cell $I / V$ relation is shown under control conditions as well as in the presence of $0.5 \mu \mathrm{M}$ AMPA (Fig. 3A). There was an inward shift over the entire potential range examined. Subtraction of the two $I / V$ curves results in the $I / V$ relation of the current activated by
Figure 4. NMDA depolarized mPRF neurons. $A$, Pressure application of NMDA results in depolarization of mPRF neurons (left panel). B, Under voltage clamp, NMDA treatment results in an inward current associated with a small increase in conductance. $C$, NMDA-induced inward current was blocked reversibly by AP5 (60 $\mu \mathrm{M})$.

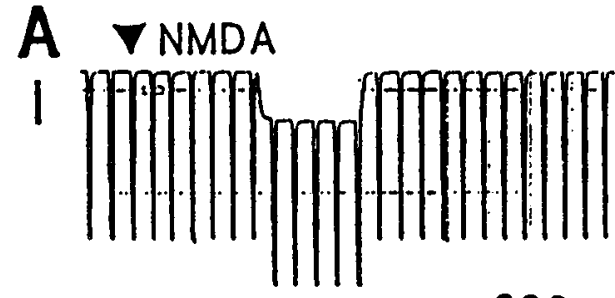

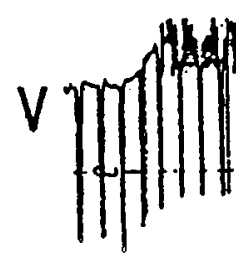

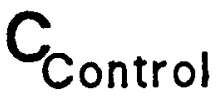

NMDA

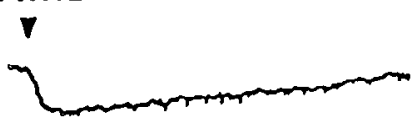

$B$

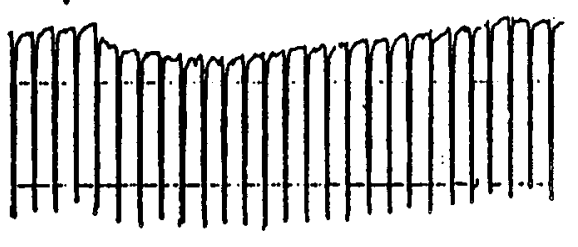

300 pA 1 minute
Recovery

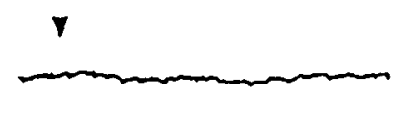

7

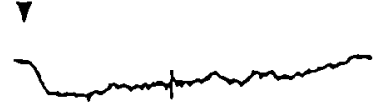




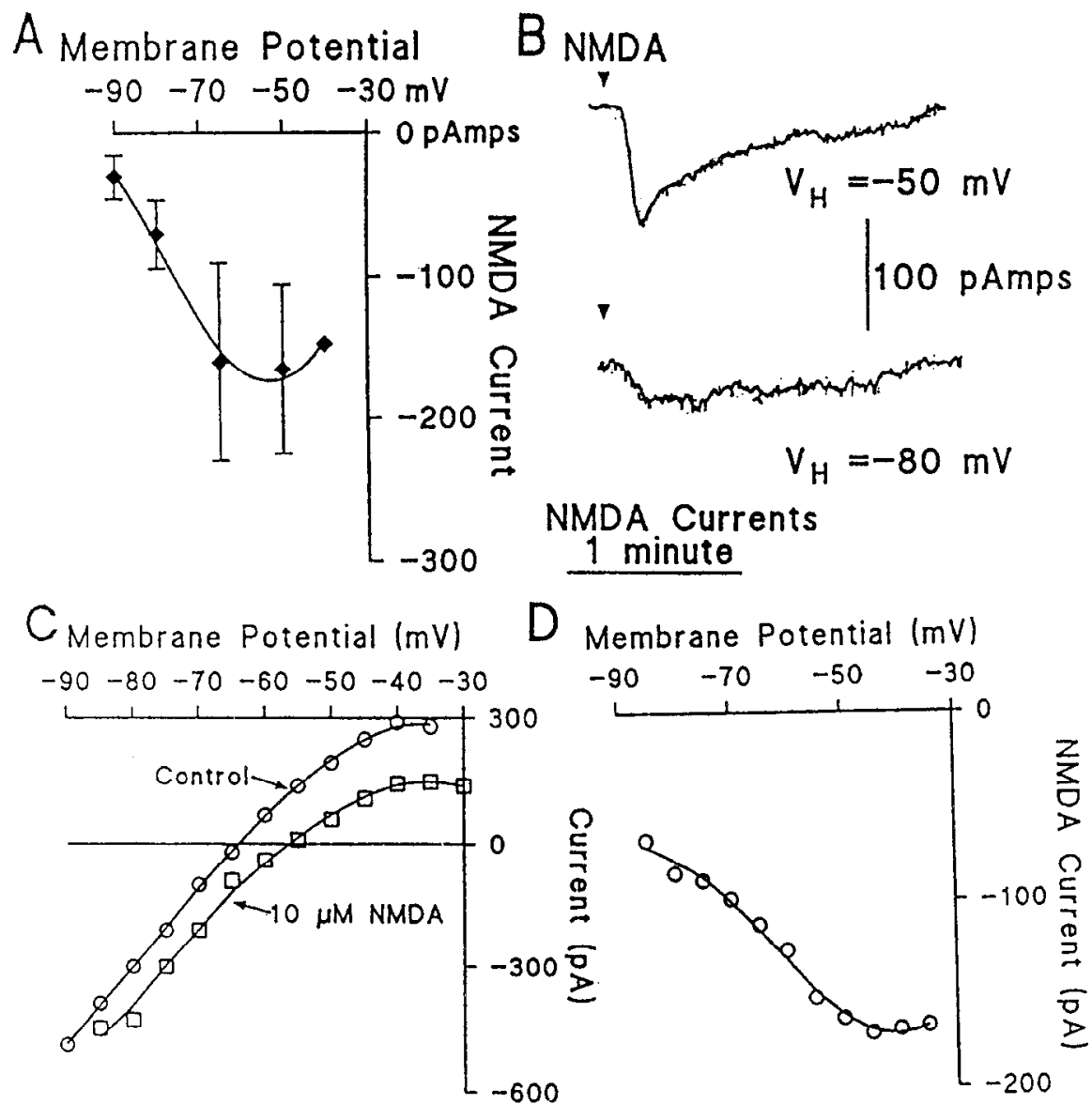

Figure 5. NMDA currents have a nonlinear voltage dependence. $A$, NMDA currents are recorded at different membrane potentials (error bars indicate SD, $n=3$; at $-40 \mathrm{mV}, n=2$ ). $B$, Individual NMDA current at -50 and $-80 \mathrm{mV}$ further demonstrates the enhanced current at more depolarized membrane potentials. $C$, The effect of NMDA on the steady-state $I / V$ relation was also examined. NMDA shifted the $I / V$ curve inward in a nonlinear fashion. $D$, Subtraction of control and NMDA treatment $I / V$ relations gives the NMDA $I / V$ relation, which is nonlinear and has a region of negative slope conductance at potentials more negative than $-45 \mathrm{mV}$
AMPA (Fig. $3 B$ ). This $I / V$ relation is linear and consistent with a voltage-insensitive conductance having a reversal potential near $0 \mathrm{mV}(n=3)$.

Kainate had a similar action on the steady-state current-voltage relation. Kainate treatment shifted the $I / V$ relation inward (Fig. 3C). The kainate-induced current (Fig. 3D) was linear with respect to membrane potential, and its slope was consistent with a reversal potential near $0 \mathrm{mV}(n=2)$.

\section{NMDA responses}

Application of NMDA by superfusion (1-10 $\mu \mathrm{M})$ or by pressure (200 $\mu \mathrm{M}$ in the pipette) resulted in depolarization (Fig. 4A). There was no clear change in the input resistance of the neuron during the NMDA-induced depolarization, even when the membrane potential was returned to the original resting potential. This was typical of recordings of membrane input resistance during NMDA treatment. Some neurons displayed increases in input resistance as assessed by current step injection.

Under voltage clamp, application of NMDA elicited an inward current (Fig. 4B). We tested whether the NMDA-elicited current was sensitive to the NMDA receptor antagonist AP5. NMDA-induced currents were reversibly blocked by AP5 (60 $\mu \mathrm{M} ; n=3$; Fig. $4 C$ ).

In other vertebrate central neurons (see review by Mayer and Westbrook, 1987), NMDA-activated conductances are voltage dependent. We examined the voltage dependence of NMDAmediated currents in mPRF neurons. NMDA currents increased in amplitude with depolarization (Fig. $5 A$ ) with as much as a fivefold increase in amplitude over the potential range tested $(-80$ to $-50 \mathrm{mV}$; Fig. $5 B$ ). Further hyperpolarization of the membrane potential never resulted in reversal of the inward current to an outward current $(n=5)$.

To characterize the voltage dependence of the NMDA induced current further, the effect of NMDA on the steady-state $I / V$ relation was examined. The steady-state $I / V$ relation was recorded during ramp voltage commands $(2.5 \mathrm{mV} / \mathrm{sec})$ over the range of -110 to $-40 \mathrm{mV}$ (Fig. $5 \mathrm{C}$ ). The steady-state $I / \mathrm{V}$ relation recorded during NMDA treatment was subtracted from that recorded prior to drug treatment, resulting in the NMDAsensitive current (Fig. 5D). In every case, the subtracted NMDA current was voltage dependent $(n=5)$, increasing with depolarization with a maximal inward current near $-40 \mathrm{mV}$. The voltage dependence of the NMDA response in other CNS neurons results from the voltage-sensitive channel block by magnesium ions (Mayer et al., 1984; Nowak et al., 1984). We have examined the sensitivity of the NMDA responses in the mPRF to magnesium and found that superfusion of the slice with magnesium-free ACSF resulted in enhancement of the NMDA current (Fig. 6A). This effect was slow in onset $(>10 \mathrm{~min}$ ) but reversed rapidly $\left(<2 \mathrm{~min}\right.$ after the addition of $1.6 \mathrm{mM} \mathrm{Mg} \mathrm{Mg}^{2+}$ to the perfusate). Comparison of the NMDA-induced current in control and in "zero" magnesium ACSF indicates that in the absence of magnesium NMDA current is enhanced in a voltagedependent manner, the enhancement being more pronounced at hyperpolarized potentials (Fig. $6 B-D$ ). 


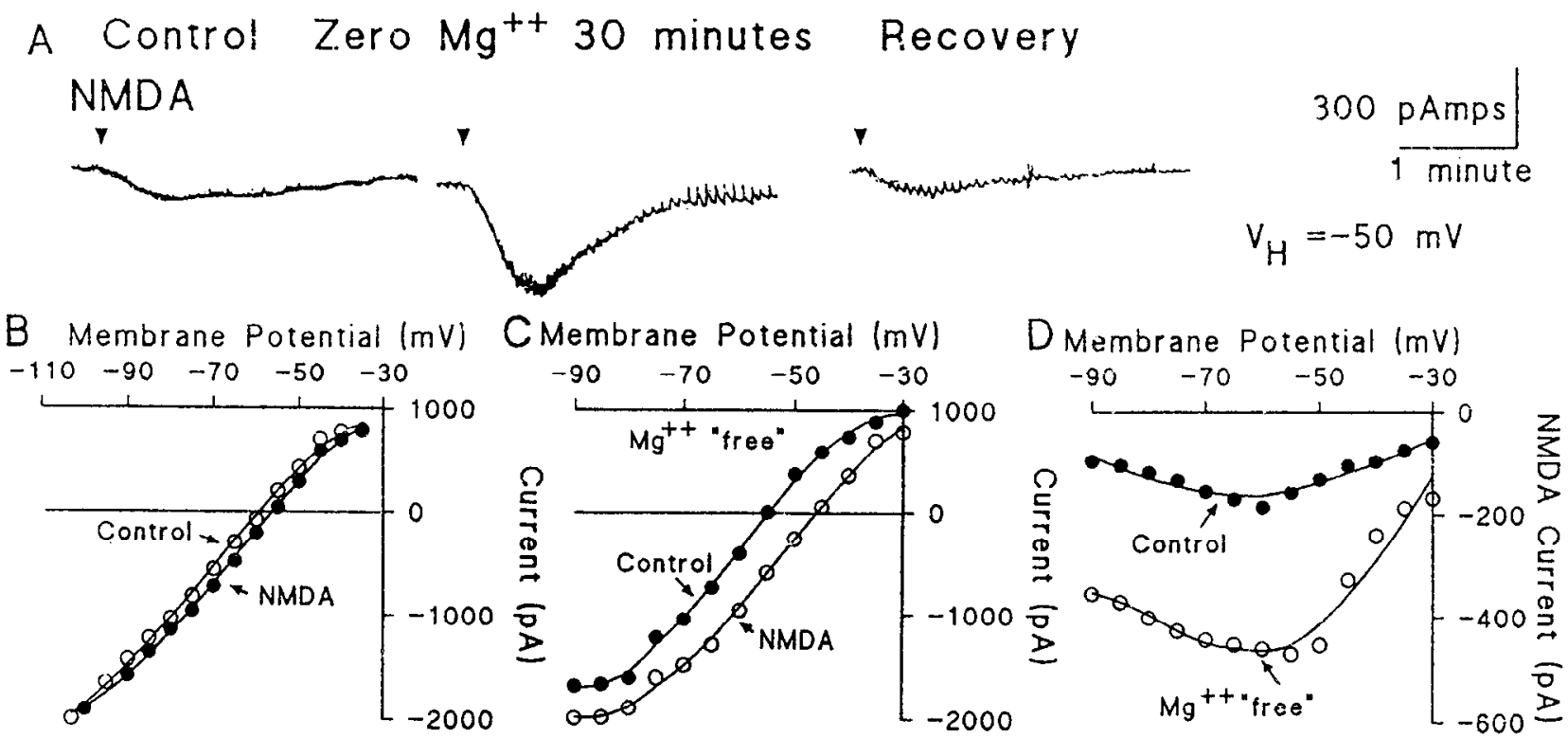

Figure 6. NMDA current is $\mathrm{Mg}^{2+}$ sensitive. $A$, NMDA currents are enhanced response following washout of $\mathrm{Mg}^{2+}$. $\mathrm{Return}^{2}$ to normal [Mg ${ }^{2+}$ ] results in rapid ( $<2 \mathrm{~min}$ ) reduction of the NMDA current to control levels. $B$, Steady-state $I / V$ curves in control and NMDA treatment conditions are shown. NMDA causes a small inward shift in the steady-state $I / V$ curve in this mPRF neuron. $C$, Following 30 min of treatment with $\mathrm{Mg}^{2+}$ "free" ACSF, the steady-state $I / V$ curves were recorded again. The inward shift in the presence of NMDA was enhanced. $D$, The subtracted NMDAsensitive currents in control and $\mathrm{Mg}^{2+}$ " "free" ACSF are shown, indicating the enhanced NMDA current, particularly at potentials positive to -40 $\mathrm{mV}$.

\section{EPSPS}

EPSPs could be evoked by stimulation of the contralateral pontine reticular formation, using $100 \mu \mathrm{sec}$ extracellular current pulses delivered from a bipolar stimulating electrode placed on the contralateral mPRF. Following treatment with $5 \mu \mathrm{M}$ strychnine [the majority of spontaneous postsynaptic potentials (PSPs) were blocked by $1 \mu \mathrm{M}$ strychnine], short-latency (1-2 msec), depolarizing EPSPs could be evoked that were reversibly depressed by kynurenic acid (Fig. $7 A$ ). The kynurenate depression

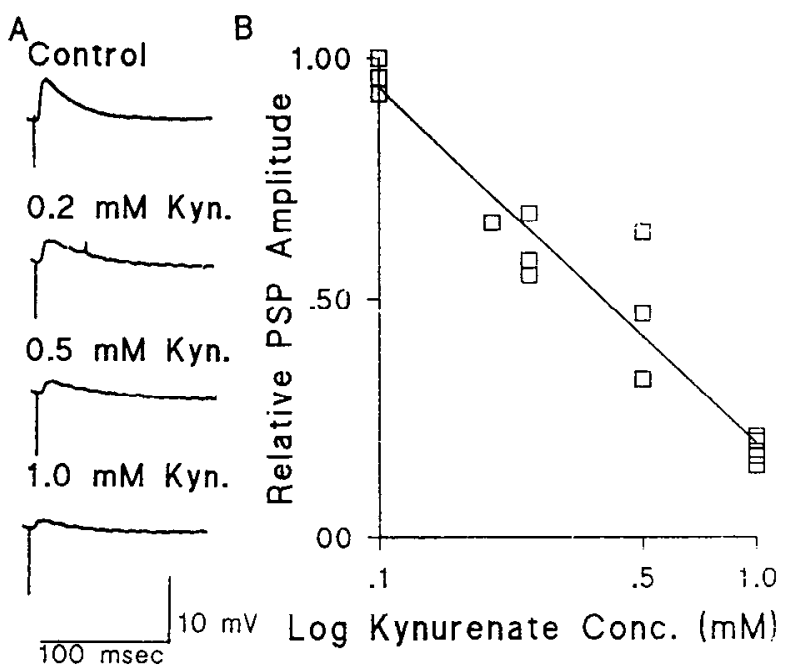

Figure 7. EAA-mediated synaptic potentials can be evoked in the MPRF. $A$, EPSPs were elicited by stimulation of the contralateral mPRF ( $5 \mu \mathrm{M}$ strychnine present). These EPSPs are blocked in a concentrationdependent manner by kynurenate. $B$, The log concentration-response relation for kynurenate block of EPSPs indicates an apparent $K_{D}$ near $300 \mu \mathrm{M}$. of evoked EPSPs was concentration dependent with an apparent $K_{D}$ near $300 \mu \mathrm{M}$ (Fig. $7 B$ ). Kynurenate $(1 \mathrm{mM})$ never completely blocked the EPSP, so it is possible that a non-EAA component or a metabotropic FAA (Charpak and Gähwiler, 1991) receptormediated component was present in the evoked EPSPs.

The strychnine-insensitive EPSPs were voltage dependent. Hyperpolarization of the membrane potential reduced both the amplitude and the duration of the EPSP (Fig. 8A). At more depolarized membrane potentials, the EPSP appeared to be biphasic in composition in some responses. This result was consistent with the presence of an NMDA component of the EPSP, so the sensitivity of the EPSP to selective blockers of nonNMDA and NMDA receptors was examined. DNQX, a selective antagonist of non-NMDA EAA receptors, was employed to determine the relative contribution of non-NMDA receptors in these synaptic potentials. DNQX $(20 \mu \mathrm{M})$ depressed all evoked EPSPs examined ( $n=20$; range, $40-90 \%$; Fig. $8 B$ ). In the presence of DNQX $(20 \mu \mathrm{M})$, addition of AP5 (50-60 $\mu \mathrm{M})$ further reduced the EPSP in 5 of 12 neurons tested (Fig. $8 B$ ).

\section{Discussion}

Our results indicate that almost all neurons of the mPRF contain functional receptors for EAAs. Most mPRF neurons have each of the three subtypes of ionotropic receptors. The presence of these receptors is consistent with a role of EAAs in synaptic transmission in the mPRF.

The non-NMDA agonists kainate and AMPA had similar actions on $\mathrm{MPRF}$ neurons. Both agonists caused depolarizations associated with inward currents as has been reported for these agents in other central neurons. Kainate $(1-10 \mu \mathrm{M})$ and AMPA $(0.3-1.0 \mu \mathrm{M})$ activated inward currents that were readily reversed with washout. Consistent with the reported actions of these two agents on CNS neurons, the currents had no apparent voltage dependence (Maycr and Westbrook, 1985). It was not possible under our recording conditions to demonstrate reversal 
A

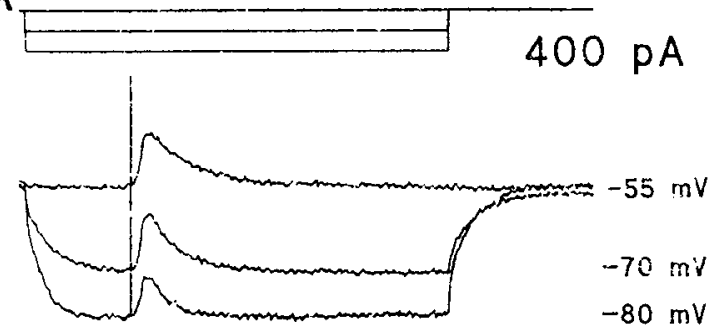

$10 \mathrm{mV}$

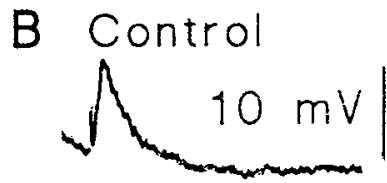

DNQX

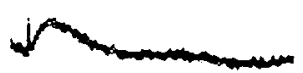

$D N Q X+A P 5$

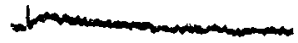

Figure 8. Evoked EPSPs consist of non-NMDA and NMDA components. $A$, EPSPs are voltage dependent. Both amplitude and duration of the EPSP are enhanced at more depolarized membrane potentials. B, Evoked EPSP (5 $\mu \mathrm{M}$ strychnine present) is depressed by DNQX $(20 \mu \mathrm{M})$. The DNQX-resistant component of the EPSP is further reduced by treatment with AP5 $(60 \mu \mathrm{M})$, indicating that NMDA receptors can be activated by synaptically released transmitter. potentials for these responses directly. However, the conductance activated by kainate and AMPA in the MPRF is similar to that reported in other CNS neurons.

In all respects, the actions of NMDA on MPRF neurons are qualitatively similar to the actions of this EAA on other mammalian central neurons. NMDA responses in the MPRF share the voltage dependence reported for these responses in the spinal cord neurons (Mayer and Westbrook, 1985), hippocampal neurons (Coan and Collingridge, 1985), and cortical neurons (Ascher and Nowak, 1988). In a number of neurons, we were not able to maintain voltage control at the depolarized potentials required to demonstrate a positive slope conductance. These experiments were complicated by the activation of inward currents in this region of the $I / V$ relation, so we have not attempted to establish the voltage dependence of NMDA currents in a rigorous quantitative fashion.

NMDA responses in the mPRF are sensitive to magnesium in a manner consistent with the block of NMDA-activated channels by $\mathrm{Mg}^{2+}$ in spinal cord neurons (Nowak et al., 1984). The slow time course of the enhancement of the NMDA currents when magnesium-free ACSF was introduced suggests that most of the magnesium must be removed before the magnesium block of NMDA currents is relieved. The $K_{D}$ for magnesium block of NMDA currents has been reported to be near $100 \mu \mathrm{M}$ (Mayer and Westbrook, 1985).

The block of the NMDA current by AP5 is consistent with the conclusion that receptors activated by NMDA in the MPRF are similar to NMDA receptors found in other mammalian CNS neurons. AP5 has been shown to displace specifically NMDA in binding assays (Monaghan and Cotman, 1985; Cotman and Monaghan, 1987), as well as to block NMDA responses preferentially in spinal cord and hippocampal neurons (see review by Mayer and Westbrook, 1987).

Based upon the ubiquitous presence of postsynaptic responses of $\mathrm{mPRF}$ neurons to EAA receptor agonists, it is likely one or more of these receptors are involved in synaptic transmission in the mPRF. The stimulations employed in the present study to elicit PSPs almost certainly resulted in the activation of axons of both reticular and nonreticular origin. All excitatory fast PSPs were antagonized by greater than $90 \%$ by kynurenate. In light of the prevalence of reticulo-reticular connections, it is likely that a component of the EAA-mediated synaptic responses we examined were of reticulo-reticular origin. In any case, it is evident from the results presented here that EAA receptor-mediated synaptic transmission is important for reticular forma- tion function. The presence of both kainate and quisqualate receptors on these neurons makes either receptor a reasonable candidate for rapid excitatory neurotransmission.

The synaptic activation of NMDA receptors is of interest since these receptors mediate a more specialized form of transmission in regions where they have been examined (Coan and Collingridge, 1985; Nelson et al., 1986; Gallagher and Hasuo, 1989; Pan and Williams, 1989; Yoshimura and Jessell, 1990). From the present results, it is not clear whether activation of NMDA receptors is limited to a functionally distinct subset of EAA synapses within the MPRF or whether NMDA receptors are involved in mPRF synaptic transmission in general. We did not attempt to maximize the NMDA receptor-mediated component of the EPSP by depolarization or by removal of magnesium. It is likely that the incidence of AP5-sensitive components of the synaptic potential would have been greater under these conditions.

The role of NMDA receptors in synaptic plasticity seems to be established (Collingridge et al., 1983; Harris et al., 1984; see review by Collingridge and Bliss, 1987), and their role in a form of slow transmission is also becoming appreciated. The presence of robust responses to NMDA on $\mathrm{MPRF}$ neurons raises the possibility that these receptors may also mediate specialized forms of synaptic transmission and possibly function in plasticity of reticular formation circuits. With the onset of REM sleep, mPRF neurons increase their firing rate and are depolarized by an accompanying EPSP barrage consistent with a sustained increase in excitatory transmission (Ito and McCarley, 1984). This long-lasting change may involve NMDA receptor activation and play a role in behavioral state-related changes reported in this region.

\section{References}

Ascher P, Nowak L (1988) The role of divalent cations in the $N$ methyl-D-aspartate responses of mouse central neurones in culture. J Physiol (Lond) 399:247-266.

Charpak S, Gähwiler BH (1991) Glutamate mediates a slow synaptic response in hippocampal slice cultures. Proc R Soc Lond [Biol] 243: 221-226.

Coan FJ, Collingridge GI. (1985) Magnesium ions block an $N$-methylD-aspartate receptor mediated component of synaptic transmission in rat hippocampus. Neurosci Lett 53:2126.

Collingridge GL, Bliss TVP (1987) NMDA receptors-their role in long-term potentiation. Trends Neurosci 10:288-293.

Collingridge GL, Kehl SJ, McLennan H (1983) Excitatory amino acids in synaptic transmission in the Schaffer-commissural pathway of the rat hippocampus. J Physiol (Lond) 334:33-46. 
Cotman CW, Monaghan DT (1987) Chemistry and anatomy of excitatory amino acids. In: Psychopharmacology: the third generation of progress (Meltzer HY, ed), pp 197-210. New York: Raven.

Davis M (1984) The mammalian startle response. In: Neural mechanism of startle behavior (Eaton RC, ed), pp 241-263. New York: Plenum.

Gallagher JP, Hasuo H (1989) Excitatory amino acid receptor mediated EPSPs in rat dorsolateral septal nucleus neurons in vitro. $\mathrm{J}$ Physiol (Lond) 418:353-365.

Grantyn R, Baker R, Grantyn A (1980) Morphological and physiological identification of excitatory pontine reticular neurons projecting to the cat abducens nucleus and spinal cord. Brain Res 198:221-228.

Harris EW, Ganong AH, Cotman CW (1984) Long-term potentiation in the hippocampus involves activation of $N$-methyl-D-aspartate receptors. Brain Res 323:132-137.

Honore T, Lauridsen J, Krogsgaard-Larsen P (1982) The binding of ${ }^{3} \mathrm{H}$ AMPA, a structural analogue of glutamic acid, to rat brain membranes. J Neurochem 38:173-178.

Ito K, McCarley RW (1986) Physiological studies of brainstem reticular connectivity. I. Responses of mPRF neurons to stimulation of bulbar reticular formation. Brain Res 409:97-110.

Jones BE (1990) Immunohistochemical study of choline acetyltransferase-immunoreactive processes and cells innervating the pontomedullary reticular formation in the rat. J Comp Neurol 295:485514.

Jordan LM (1991) Brainstem and spinal cord mechanisms for the initiation of locomotion. In: Ncurological basis of locomotion (Shimamura M, Grillner S, Edgerton VR, eds), pp 3-20. Tokyo: Japan Scientific Societies.

Lai YY, Siegel JM (1988) Medullary regions mediating atonia. J Neurosci 8:4790-4796.

Lai YY, Siegel JM (1991) Pontomedullary glutamate receptors mediating locomotion and muscle tone suppression. J Neurosci 11:29312937.

Mayer ML, Westbrook GL (1985) The action of $N$-methyl-D-aspartic acid on mouse spinal neurones in culture. J Physiol (Lond) 361:6590.

Mayer ML, Westbrook GL (1987) The physiology of excitatory amino acids in the vertebrate central nervous system. Prog Neurobiol 28: 197-296.

Mayer ML, Wcstbrook GL, Guthric PB (1984) Voltage-dependent block by $\mathrm{Mg}^{2+}$ of NMDA responses in spinal cord neurones. Nature 309:261-263.
McCarley RW, Ito K, Rodrigo-Angulo ML (1987) Physiological studies of brainstem reticular connectivity. II. Responses of mPRF neurons to stimulation of mesencephalic and contralateral pontine reticular formation. Brain Res 409:111-127.

Mitani A, Ito K, Mitani Y, McCarley RW (1988) Morphological and electrophysiological identification of gigantocellular tegmental field neurons with descending projections in the cat: I. Pons. J Comp Neurol 268:527-545.

Monaghan DT, Cotman CW (1982) Distribution of ${ }^{3} \mathrm{H}-\mathrm{kainic}$ acid binding sites in rat CNS as determined by autoradiography. Brain Res 252:91-100.

Monaghan DT, Cotman CW (1985) Distribution of $N$-methyl-D-aspartatc-sensitive L-' $\mathrm{H}$-glutamatc-binding sites in rat brain. J Neurosci 11:2909-2919.

Monaghan DT, Yao D, Cotman CW (1984) Distribution of $\left[{ }^{3} \mathrm{H}\right]-$ AMPA binding sites in rat CNS as determined by quantitative autoradiography. Brain Res 324:160-164.

Nelson PG, Pun RYK, Westbrook GL (1986) Synaptic excitation of mouse spinal cord neurones: receptor pharmacology and behavior of synaptic currents. J Physiol (Lond) 372:169-190.

Noga BR, Kettler J, Jordan LM (1988) Locomotion produced in mesencephalic cats by injections of putative transmitter substance and antagonists into the medial reticular formation and pontomedullary locomotor strip. J Neurosci 8:2074-2086.

Nowak L, Bregestovski P, Ascher P, Herbert A, Prochiantz A (1984) Magnesium gates glutamate-activated channels in mouse central neurones. Nature 307:462-465.

Pan ZZ, Williams JT (1989) GABA- and glutamate-mediated synaptic potentials in rat dorsal raphe neurons in vitro. $\mathrm{J}$ Neurophysiol 61: 719-726.

Peterson BW (1979) Reticulospinal projections to spinal motor nuclei. Annu Rev Physiol 41:127-140.

Rainbow TC, Wieczorek CM, Halpain S (1984) Quantitative autoradiography of binding sites for [ $\left.{ }^{3} \mathrm{H}\right]-A M P A$, a structural analogue of glutamic acid. Brain Res 309:173-177.

Shammah-Lagnado SJ, Negrao N, Ricardo JA (1987) Afferent connections of the nuclei reticularis pontis oralis and caudalis: a horseradish peroxidase study in the rat. Neuroscience 20:961-989.

Steriade M, McCarley RW (1990) Brainstem control of wakefulness and sleep. New York: Plenum.

Yoshimura M, Jessell T (1990) Amino acid-mediated EPSPs at primary afferent synapses with substantia gelatinosa neurones in the rat spinal cord. J Physiol (Lond) 430:315-335. 